\title{
Recherche
}

\section{Prevalence of overweight and obesity in a provincial population of Canadian preschool children}

\author{
Patricia M. Canning, Mary L. Courage, Lynn M. Frizzell
}

ß S See related article page 243

Abstract

Background: More and more school-aged children in Canada and elsewhere are becoming overweight or obese. Many countries are now reporting a similar trend among preschool children. However, little information is available on the prevalence of overweight and obesity among preschool children in Canada. In addition, available data are based on reported rather than measured heights and weights. We conducted this study to determine the prevalence of overweight and obesity, using measured heights and weights, in the 1997 cohort of children aged 3-5 years born in Newfoundland and Labrador.

Methods: We calculated the body mass indices (BMIs) using heights and weights measured by public health nurses during the province-wide Preschool Health Check Program conducted between October 2000 and January 2003. Descriptive data on the children's BMIs and prevalence estimates were generated and analyzed by sex and age with the use of the classification system recommended by the International Obesity Task Force.

Results: Data were available for 4161 of the 5428 children born in 1997; boys and girls were equally represented $(50.1 \%$ and $49.9 \%$ respectively). Overall, $25.6 \%$ of the preschool children in the cohort were overweight or obese. The rates did not differ significantly by sex or age group

Interpretation: These results indicate that a high proportion of children aged 3-5 years in Newfoundland and Labrador are overweight or obese. It appears that prevention measures should begin before the age of 3 years.

CMAJ 2004;171(3):240-2

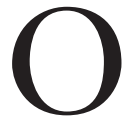
verweight and obesity are global health problems. In Canada, recent reports have indicated that $57 \%$ of adult men and $35 \%$ of adult women are overweight or obese. ${ }^{1}$ The rates of childhood and adolescent obesity are also high and are rising throughout the developed world. Canada has reported that the rates of overweight and obesity (combined) among school-aged boys and girls increased from $15.0 \%$ in 1981 to $35.4 \%$ and $29.2 \%$ respectively in 1996. ${ }^{2}$ In Australia, data collected in 1985 and 1995 showed that the prevalence of overweight and obesity among children $7-15$ years old increased from $10.7 \%$ to $20.0 \%$ among boys and from $11.8 \%$ to $21.5 \%$ among girls. ${ }^{3}$ In the United States, similarly increasing rates were reported over the same period, ${ }^{4}$ and the trends are continuing. ${ }^{5}$
The few studies that have reported on overweight and obesity among preschool children have indicated that a trend toward increasing weight is also occurring in this age group. In the United States, Ogden and colleagues 5 found that the prevalence of obesity ( $>95$ th percentile) increased from $7.2 \%$ in $1988-1994$ to $10.4 \%$ in 1999-2000 among children 2-5 years old. Although there is little information available on the prevalence among Canadian preschool children, an Ontario study of a preschool program noted that more than $20.0 \%$ of approximately 300 participants were overweight $(>90$ th percentile). ${ }^{6}$ Since it has been shown that interventions are not usually successful once overweight and obesity have occurred, ${ }^{7}$ it is important to establish the age at which unhealthy body weights begin to emerge.

We conducted this study to determine the prevalence of overweight and obesity, using measured heights and weights, in a provincial population of preschool-aged children in Canada. Most studies of overweight and obesity in young children have relied on heights and weights reported by parents, data that are known to be less accurate than direct measures. ${ }^{8}$ In fact, the most recent estimates of the prevalence among Canadian children based on direct measurements were those obtained in the 1981 Canada Fitness Survey. The results of our study will aid in determining the age group at which prevention measures should begin and will establish a baseline against which these measures may be evaluated and from which future trends may be monitored.

\section{Methods}

Data were obtained from the records of children who were born in the province of Newfoundland and Labrador in 1997 and who participated in the Preschool Health Check Program, a province-wide screening program conducted by public health nurses before school entry. Although all of the children were born in 1997, because of the variability in the timing of the Preschool Health Check, children's ages ranged from 3.5 years to 5.5 years.

As part of the screening, all children were weighed and their heights measured by the nurse using a standardized procedure. Children were weighed, wearing light clothing, on a calibrated mechanical or electronic step scale. In addition, we obtained the date of the Preschool Health Check and the child's date of birth and sex from the Program's records. 
Each child's body mass index (BMI, $\left.\mathrm{kg} / \mathrm{m}^{2}\right)$ was calculated from the height and weight measures. We classified each child as being "overweight," "obese" or "normal" using previously published age- and sex-specific BMIs for children aged 2-18 years, as modified from the accepted cut-off values for adults. ${ }^{9}$

\section{Results}

Data were received for 4469 of the 5428 children born in 1997. Because information was missing for 308 children, the final sample included 4161 children. This sample represents $76.7 \%$ of the 1997 birth cohort ${ }^{10}$ and $79.2 \%$ of the children who were subsequently enrolled in kindergarten in 2002. ${ }^{11}$ Boys and girls were equally represented $(50.1 \%$ and $49.9 \%$ respectively). The response rates did not vary significantly by region, ranging from $73.0 \%$ to $84.0 \%$. A description of the sample is presented in Table 1.

The rates of overweight and obesity in this preschool population were high (Fig. 1). There were no significant differences between boys and girls in the prevalence of overweight or obesity $(p \geq 0.05)$. Similarly, there were no significant differences between age groups in the prevalence of overweight or obesity $(p \geq 0.05)$. There were no significant sex-by-age interactions in prevalence.

\section{Interpretation}

This study represents the first province-wide report on the prevalence of overweight and obesity among preschool children in Canada based on directly measured heights and weights. Our results indicate that more than 1 in 4 preschool children in Newfoundland and Labrador are already overweight or obese. The magnitude of the problem may reflect the fact that the province's rates of overweight and obesity among older children and adults are the highest in the country.

Without comparable data from other provinces, we do not know whether the prevalence observed in our study would be seen in other provinces. However, the prevalence of overweight and obesity among older children and adults is increasing everywhere in Canada, having doubled between 1981 and 1996 in 9 out of 10 provinces. ${ }^{12}$ In fact, Willms and colleagues ${ }^{12}$ concluded from their study of Canadian children aged 7-13 years that the risk of being overweight is related more to the secular trend than to demographic or geographic variables. Recent reports of the prevalence among teenagers in Canada indicate that the trend is continuing. ${ }^{13}$

The prevalence of overweight and obesity in Newfoundland and Labrador is similar to the prevalence among
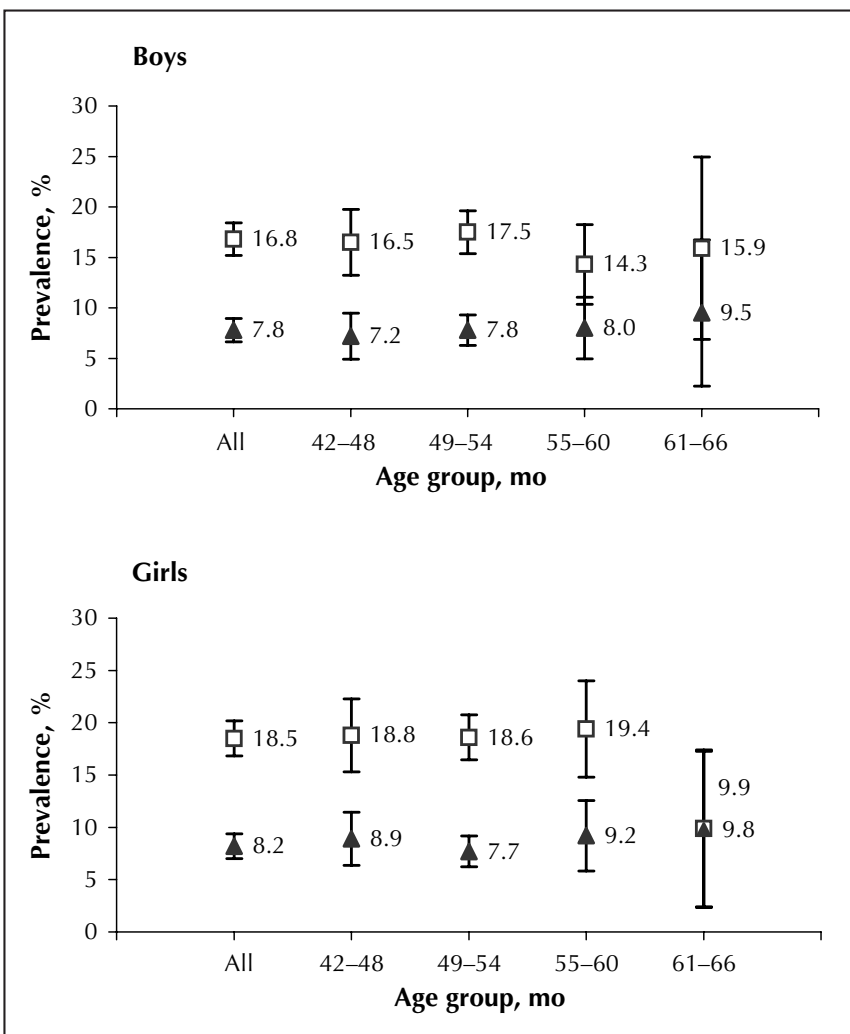

Fig. 1: Prevalence of overweight (squares) and obesity (triangles) among preschool children in Newfoundland and Labrador, by sex and age group. Error bars represent $95 \%$ confidence intervals.

Table 1: Heights, weights and BMIs of preschool children in Newfoundland and Labrador, by age group

\begin{tabular}{lccccc}
\hline & \multicolumn{5}{c}{ Age group, mo; mean value (SD) } \\
\cline { 2 - 6 } Sex; variable & $42-48$ & $49-54$ & $55-60$ & $61-66$ & All \\
\hline Boys & $n=497$ & $n=1223$ & $n=300$ & $n=63$ & $n=2083$ \\
Height, cm & $104.2(4.4)$ & $106.4(4.6)$ & $108.9(4.5)$ & $110.9(5.3)$ & $106.3(4.9)$ \\
Weight, kg & $18.3(3.1)$ & $19.0(3.1)$ & $19.7(3.2)$ & $20.8(4.3)$ & $19.0(3.2)$ \\
BMI, kg/m & $16.8(2.1)$ & $16.8(1.9)$ & $16.6(1.9)$ & $16.8(2.0)$ & $16.7(2.0)$ \\
Girls & $n=484$ & $n=1250$ & $n=283$ & $n=61$ & $n=2078$ \\
Height, cm & $102.7(4.6)$ & $105.2(4.5)$ & $108.2(5.2)$ & $110.7(6.4)$ & $105.2(5.0)$ \\
Weight, kg & $17.6(2.9)$ & $18.3(3.2)$ & $19.4(3.6)$ & $20.1(3.8)$ & $18.4(3.3)$ \\
BMI, kg/m & $16.6(2.2)$ & $16.5(2.0)$ & $16.5(2.4)$ & $16.3(1.9)$ & $16.5(2.1)$ \\
\hline
\end{tabular}

Note: $\mathrm{BMI}=$ body mass index, $\mathrm{SD}=$ standard deviation. 
preschoolers in other countries based on measured heights and weights. A 1998 United Kingdom study reported a prevalence of $23.6 \%$ among children aged $2.9-4$ years. ${ }^{14}$ In Australia, $18.0 \%$ of children $2-6$ years old were overweight or obese. These countries also reported increasing prevalence of overweight and obesity among older children and adults.

One aim of our study was to determine the age at which overweight and obesity emerge in preschool children. We found that more than $25 \%$ of children as young as 3.5 years, the youngest in our study, were overweight or obese. A report from the United States has indicated that children less than 2 years old are showing a trend toward a higher weight for height. ${ }^{15}$ Together these results clearly indicate the need to examine adiposity in children less than 3.5 years of age. In places like Newfoundland and Labrador, and other parts of Canada and other developed countries with well-developed health and community nursing systems, monitoring and prevention could be incorporated into existing prenatal and child health programs without a substantial increase in costs. Our data provide a basis upon which future trends in the Canadian preschool population may be monitored and against which prevention measures may be evaluated.

This article has been peer reviewed.

From the Faculty of Education (Canning), the Department of Psychology (Courage) and the Centre of Excellence for Children and Adolescents with Special Needs (Canning, Courage, Frizzell), Memorial University, St. John's, Nfld.

Competing interests: None declared.

Contributors: The authors worked collaboratively on the conception and design of the study, and the acquisition of data. Patricia Canning and Lynn Frizzell conducted the analyses and prepared the results tables and initial draft of the article. All authors collaborated on the final interpretation, drafting and editing of the article. They gave final approval of the version to be published.

Acknowledgements: We thank the public health nurses and regional health and community services boards of Newfoundland and Labrador for providing the data for this study. We also thank Dr. Tim Seifert for his helpful comments on the manuscript.

This research was supported by the Centre of Excellence for Children and Adolescents with Special Needs. The centre is 1 of 5 Centres of Excellence for Children's Well-Being funded by Health Canada. The views expressed herein do not necessarily represent the official policies of Health Canada.

\section{References}

1. Tremblay MS, Katzmarzyk PT, Willms JD. Temporal trends in overweight and obesity in Canada, 1981-96. Int 7 Obes Relat Metab Disord 2002;26(4):538-43.

2. Tremblay MS, Willms JD. Secular trends in the body mass index of Canadian children [published erratum appears in CMA7 2001;164(7):970]. CMA7 2000; 163(11):1429-33.

3. Magarey AM, Daniels LA, Boulton TJ. Prevalence of overweight and obesity in Australian children and adolescents: reassessment of 1985 and 1995 data against new standard international definitions. Med F Aust 2001;174:561-4.

4. The Surgeon General's call to action to prevent and decrease overweight and obesity. Rockville (MD): US Department of Health and Human Services, Public Health Service, Office of the Surgeon General; 2001.

5. Ogden C, Flegal K, Carroll M, Johnson C. Prevalence and trends in overweight among US children and adolescents, 1999-2000. 7AMA 2002;288(14):1728-32.

6. Peters R De V. Better beginnings, better futures: overview of lessons learned. Kingston (ON): Queen's University, Research Coordination Unit; 2001.
7. Pinhas-Hamiel O, Zietler P. Who is the wise man? The one who foresees consequences: childhood obesity, new associated comorbidity and prevention. Prev Med 2000;31:702-5.

8. Maynard LM, Galuska DA, Blanck HM, Serdula MK. Maternal perceptions of weight status of children. Pediatrics 2003;111(5 Part 2):1226-31.

9. Cole TJ, Bellizzi MC, Flegal KM, Dietz WH. Establishing a standard definition for child overweight and obesity worldwide: international survey. $B M \mathcal{F}$ 2000;320:1240-3.

10. Newfoundland and Labrador Centre for Health Information. Live birth trends. Health and community services and integrated boards: Newfoundland and Labrador, 1997-2001. St. John's: The Centre; 2003. Available: www.nlchi.nf .ca/pdf/livebirth03.pdf (accessed 2004 May 26).

11. Government of Newfoundland and Labrador. Education statistics - Elemen tary-Secondary, 2002-03. St. John's: Department of Education; 2003.

12. Willms JD, Tremblay MS, Katzmarzyk PT. Geographic and demographic variation in the prevalence of overweight Canadian children. Obes Res 2003;11 (5):668-73.

13. Carriere G. Parent and child factors associated with youth obesity. Health Rep 2003;14(Suppl):29-39.

14. Bundred P, Kitchiner D, Buchan I. Prevalence of overweight and obese children between 1989 and 1998: population based series of cross sectional studies. BM7 2001;322:326-8.

15. Ogden CL, Troiano RP, Briefel RR, Kuczmarski RJ, Flegal KM, Johnson CL. Prevalence of overweight among preschool children in the United States, 1971 through 1994. Pediatrics 1997;99(4):E1.

Correspondence to: Patricia M. Canning, Centre of Excellence for Children and Adolescents with Special Needs and the Faculty of Education, Box 99, Hickman Bldg., Memorial University,

St. John's NL A1B 3X8; Fax 709 737-8677; pcanning@mun.ca

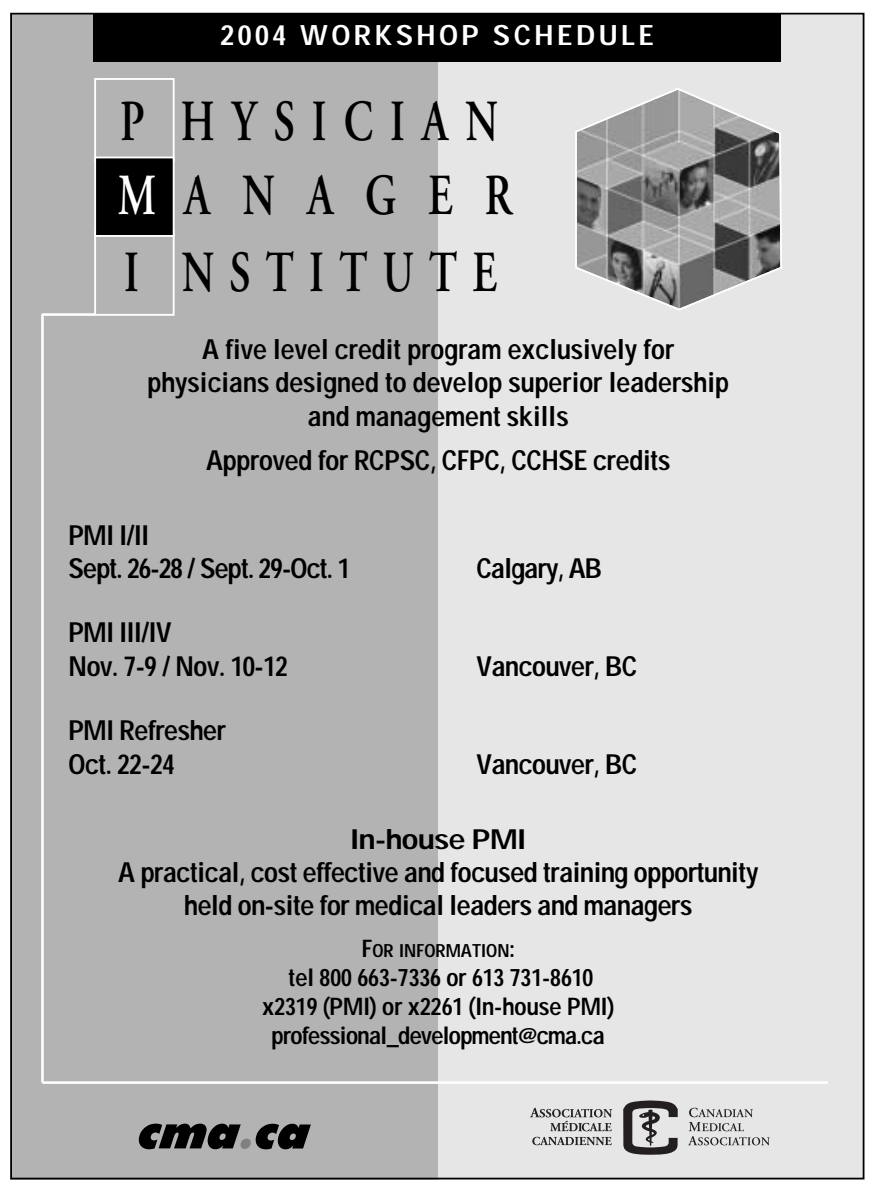

